\title{
Chemotherapy and Targeted Therapy for Gall Bladder Cancer
}

\author{
Bhawna Sirohi • Ashish Singh • P. Jagannath • \\ Shailesh V. Shrikhande
}

Received: 25 April 2014 / Accepted: 13 May 2014 / Published online: 3 June 2014

(C) Indian Association of Surgical Oncology 2014

\begin{abstract}
Gall bladder cancer is a common cancer in the Ganges belt of North-eastern India. In view of incidental diagnosis of gall bladder cancer by physicians and surgeons, the treatment is not optimised. Most patients present in advanced stages and surgery remains the only option to cure. This review highlights the current evidence in advances in systemic therapy of gall bladder cancer.
\end{abstract}

Keywords Gall bladder cancer · Targeted therapy · Chemotherapy

\section{Introduction}

Gallbladder carcinoma (GBC) is a major cause of mortality in cancer in areas of the world where it is commonly diagnosed. The prognosis associated with GBC is poor predominantly due to advanced stage at diagnosis, which is often related to lack of or nonspecific symptoms during the early stages of disease. Surgery is the only treatment modality that provides a chance of cure. However recurrence is common in the form of distant metastasis and long term survivors are less than 30 percent $[1,2]$. The incorporation of systemic chemotherapy and novel agents have been tested in many clinical trials to improve the chances of cure in resectable disease and improve survival in advanced disease.

B. Sirohi $(\bowtie) \cdot$ A. Singh

Department of Medical Oncology, TMC Tata Memorial Centre, Parel Mumbai 400012, India

e-mail: bhawna.sirohi13@gmail.com

\section{P. Jagannath}

Department of Surgical Oncology, Lilavati Hospital and Research centre, Tata Memorial Centre (TMC), Mumbai, India

\section{S. V. Shrikhande}

Department of GI \& HPB Surgery, TMC, Tata Memorial Centre (TMC), Mumbai, India

\section{Adjuvant Therapy}

Chemotherapy

The existing literature related to the adjuvant treatment in $\mathrm{GBC}$ is difficult to interpret with conflicting results. Majority of data is from retrospective studies in whom GBC has been studied along with other biliary cancers.

In contrast to patients who have margin-positive surgery, in whom locoregional recurrences are common, the pattern of disease recurrence following complete resection of GBC is both local and distant. In a series of 97 patients who underwent surgery for GBC (90 percent of whom had a margin-negative surgery), locoregional disease as the first site of recurrence occurred in 15 percent of cases; an initial recurrence involving a distant site, with or without associated locoregional recurrence was seen in 85 percent [2].s This suggests that chemotherapy could be a more rational adjuvant treatment strategy than radiotherapy (RT) or chemo radiotherapy (CRT). Retrospective series have suggested benefit from adjuvant chemotherapy [3-5]. In a multicenter trial from Japan of 140 patients comparing surgery with and without postoperative chemotherapy (two courses of mitomycin $\mathrm{C}$ and infusional 5-FU, followed by prolonged oral administration of 5-FU until tumor progression), 90 percent of patients who had positive lymph nodes showed a benefit from adjuvant chemotherapy. The five-year survival rate was higher in patients who were assigned to chemotherapy at random (26 versus 14 percent) [6]. Most centres where adjuvant chemotherapy is practised, use 5FU or Gemcitabine separately or in combination with a platinum where better efficacy has been seen in advanced stages $[7,8]$.

Chemo-Radiotherapy and Radiation Therapy

The efficacy of adjuvant radiation therapy (RT) in the treatment of GBC is not established. After surgical resection, 
postoperative external beam RT can reduce local recurrence; however effect on overall survival has not been proven due to lack of good quality clinical trials. Retrospective reviews with a small sample size in which either RT alone or CRT (generally with a concomitant fluoropyrimidine) was administered have suggested better survival [9-22]. In most situations, the conclusion was that the patients who underwent RT as a part of therapy (particularly at doses $\geq 40 \mathrm{~Gy}$ ) had better survival than those who did not. Table 1 summarizes the limited available data regarding adjuvant treatment of GBC.

Furthermore, most series included few patients, and many included various sites of the biliary system (GBC along with cholangiocarcinoma), making it difficult to draw rational conclusions. The benefit of adjuvant RT has been refuted by others $[2,23,24]$. It is possible that the apparent survival prolongation was due to selection of fitter patients for adjuvant therapy and tumor biology and was not related to the use of RT. Well designed randomized trials exclusively for GBC are needed to define the role of adjuvant radiotherapy in GBC.

\section{IORT (Intraoperative Radiotherapy)}

The limited radiation tolerance of normal tissues surrounding the gallbladder fossa led to the introduction of intraoperative radiation therapy (IORT), a technique that allows the delivery of a large dose of RT to the tumor alone, while excluding adjacent structures. Previous reports suggest an advantage of IORT for both palliation and cure [25-27]. In one nonrandomized series, 17 of 27 patients undergoing resection for T4N0-1 GBC received IORT with or without postoperative external beam RT [25]. The three-year cumulative survival following surgery along with IORT versus surgery alone was 10 versus 0 percent. The routine use of IORT is limited by availability of the same and the logistics of intraoperative treatment and currently should be part of a clinical trial as the numbers are too small to draw any definite conclusions.

\section{Meta-Analysis}

The benefits of adjuvant therapy following curative-intent resection for biliary tract malignancy (intra hepatic and extrahepatic bile ducts as well as GBC) were studied in a metaanalysis that included a single randomized trial of only chemotherapy [28], two SEER registry analyses, and 17 retrospective series, comprising 6,712 patients, of whom 1797 received adjuvant therapy. To be eligible, studies had to include patients who had curative-intent surgery alone (defined as negative [R0] or microscopically positive [R1] margins) as a control group. There were eight studies of RT and chemotherapy, three of only chemotherapy, and nine of RT alone. Only five of these were conducted in GBC, one of which has been discussed above, four studied EBRT, and two with associated chemo radiotherapy.

The following were the results:

The improvement in five-year survival with any adjuvant therapy compared with surgery alone, was not statistically significant (pooled odds ratio [OR] 0.74, $95 \%$ CI 0.55-1.01). The results were identical when gallbladder and bile duct cancers were analyzed separately. However, the survival improvement from adjuvant therapy was statistically significant when data from the two large registry series ( $n=1,233$ patients) were excluded (OR $0.53,95 \%$ CI $0.39-0.72$ ). The benefits of adjuvant treatment were modality-dependent; in a combined analysis of gallbladder and bile duct cancers, there was a significant survival benefit for chemotherapy (OR 0.39, $95 \%$ CI $0.23-0.66$ ) and chemo radiotherapy (OR $0.61,95 \% \mathrm{CI}$ $0.38-0.99$ ) but not RT alone (OR 0.98, $95 \%$ CI $0.67-1.43$ ).

Nine studies, in which at least 50 percent of the patients had margin or node positivity, were analyzed separately: Pooled data showed a statistically significant overall survival benefit for any adjuvant therapy in node-positive disease (OR 0.49, $95 \%$ CI $0.30-0.80$ ). Most of these patients (77 percent) had received only chemotherapy, while the remainder underwent CRT [28].

Table 1 Adjuvant treatment for gall bladder cancer

\begin{tabular}{|c|c|c|c|c|c|c|c|c|}
\hline Author year [ref] & Design & $\begin{array}{l}\text { Total } \\
\text { patients }\end{array}$ & $\begin{array}{l}\text { GBC } \\
{[\%]}\end{array}$ & $\begin{array}{l}\text { Adj } \\
\text { chemotherapy }\end{array}$ & Concurrent CRT & Radiotherapy & $\begin{array}{l}\text { Median } \\
\text { follow up }\end{array}$ & Survival \\
\hline Kresl 2002 [17] & Retrospective & 21 & $21[100]$ & None & 5FU bolus & $54 \mathrm{~Gy}$ & 5 years & $33 \%$ \\
\hline Czito 2005 BG [21] & Retrospective & 22 & $22[100]$ & None & 5FU bolus/CI & $45 \mathrm{~Gy}$ & 5 years & $37 \%$ \\
\hline $\begin{array}{l}\text { Ben-David } \\
\text { MA2006 [48] }\end{array}$ & Retrospective & 81 & $28[34]$ & None & 5 FU bolus $(54 \%)$ & 58.4 Gy & 1.2 years & $7 \%$ \\
\hline Duffy A 2008 [7] & Retrospective & 123 & 123 & $16(13 \%)$ & 5FU bolus $16(13 \%)$ & na & 26.6 months & 10.3 months \\
\hline Gold DG 2009 [12] & Retrospective & 73 [all R0] & 73 & None & 5FU bolus $25(34 \%)$ & 50.4Gy & na & 4.8 years \\
\hline Gonzalez 2011 [49] & Retrospective & 67 [all R0] & 67 & None & $5 \mathrm{FU}$ bolus & 45-59.4 Gy & 90 months & 42 months \\
\hline Takada 2002 [6] & $\begin{array}{l}\text { Randomised } \\
\text { control trial }\end{array}$ & 508 & 112 & $\begin{array}{c}69[\mathrm{MMC} \& \\
5 \mathrm{FU}]\end{array}$ & none & none & 5 years & $26 \%$ vs $14.4 \%$ \\
\hline Mahantshetty [1] & Retrospective & 60 & 60 & $7(12 \%)$ & $5 \mathrm{FU}+/-$ Mitomycin & $47 \mathrm{~Gy}$ & 5 years & $25 \%$ \\
\hline
\end{tabular}

5FU: 5 fluorouracil, $C R T$ : chemoradiotherapy, $M M C$ - mitomycinC, Adj: adjuvant 
Also, similar to node positive disease, a significant advantage for any adjuvant therapy was shown in patients with margin-positive disease (OR 0.36, 95 \% CI 0.19-0.68). About two-thirds of the treated R1 patients (63 percent) had received only RT as a component of adjuvant therapy, while the majority of R0 studies used chemo radiotherapy, and most of these included patients who were node-positive. Following a $\mathrm{R} 1$ resection, there was a statistically significant advantage from adjuvant RT (OR 0.33, $95 \%$ CI 0.14-0.81), while after $\mathrm{R} 0$ resection, adjuvant $\mathrm{RT}$ alone was associated with a worse survival (OR 1.26, 95 \% CI 0.88-1.79). However, since most of the patients with R0 disease had positive nodes and received a combination of chemotherapy and RT, the analogy is not well matched.

There was limited data to evaluate the benefit of chemotherapy in patients with node-negative disease. In an exploratory analysis, the benefit of adjuvant chemotherapy was greater in studies in which at least 50 percent of the patients had nodepositive or R1 disease or both, compared to studies that did not include many patients with node-positive or R1 disease.

While this analysis validates the benefit of adjuvant therapy for high-risk subgroups with GBC, it does not resolve the issue of the best treatment strategy (i.e., chemo radiotherapy versus chemotherapy alone) for high-risk patients, or fully address the advantage of adjuvant therapy for low-risk patients (i.e., node-negative). Randomized trials are urgently needed in this area.

\section{Prediction Models}

One group of authors attempted to construct a prediction model for estimating the survival advantage of adjuvant RT based on 4,180 patients with resected GBC who were reported to the National Cancer Institute Surveillance, Epidemiology and End Results (SEER) records between 1988 and 2003. Adjuvant RT was administered to 760 patients; the number who also received concomitant chemotherapy was not reported. In a multivariate analysis, male sex, older age, nonpapillary histology, and no adjuvant RT were important predictors of overall worse survival. Clinicopathological features were then used to construct a nomogram (available online) which predicted survival both with and without RT [29]. The authors reported that patients with $\geq \mathrm{T} 2$ stage, node-positive disease derived the greatest advantage from RT. However, as noted above, it is possible that the apparent survival prolongation from RT seen in this series was due to patient selection and/or tumor biology, and not due to RT.

In order to ascertain the role of chemo radiotherapy, the same authors utilized the linked SEER-Medicare database to study 1,137 Medicare beneficiaries with resected GBC who were treated between 1995 and 2005. Forty-one percent had node-positive disease, and 55 percent had T3/4 primary tumors. Overall, 126 patients received adjuvant chemotherapy, and an additional 126 received both chemotherapy and radiotherapy within six months of diagnosis, and thus, were considered to have received chemo radiotherapy. Treated patients tended to be younger and had higher $\mathrm{T}$ and $\mathrm{N}$-stages. However, propensity-score weighting was used to balance all covariates between treated and untreated groups. Multivariate regression survival analysis was performed using several different modeling methods, and the best performing of these was used to construct a nomogram (available online) [29] that calculates the expected survival benefit from adjuvant chemotherapy and chemo radiotherapy. The authors concluded that patients with $\geq \mathrm{T} 2$ or node-positive disease derived the greatest benefit from chemo radiotherapy and that in virtually all cases chemo radiotherapy outperformed chemotherapy alone [29].

\section{Neoadjuvant Therapy}

\section{Chemotherapy}

A large number of patients with GBC are locally advanced at diagnosis and as surgery remains the only curative option neo adjuvant strategy appears to be a reasonable option. Neoadjuvant chemotherapy has been evaluated in a retrospective study of 38 patients with locally advanced GBC treated at Tata Memorial Centre between Feb 2009 to May 2013 [30]. The objective of the study was to evaluate resectability rates in patients with locally advanced GBC (which was defined as GB mass infiltrating the liver $>2 \mathrm{~cm}$ without porta hepatis/ vascular involvement, GB mass adherent to hepatic flexure and duodenum and, coeliac/gastrohepatic lymphadenopathy/ portocaval and peripancreatic nodes). Chemotherapy consisted Cisplatin $25 \mathrm{mg} / \mathrm{m} 2$ and Gemcitabine $1,000 \mathrm{mg} /$ $\mathrm{m} 2$ on D1 and D8 of 21d cycle, or Gemcitabine 1,000 mg/ $\mathrm{m} 2 \mathrm{D} 1$ and oxaliplatin $100 \mathrm{mg} / \mathrm{m} 2 \mathrm{D} 2$ every 2 weeks. Of all 38 patients, 33 patients were treated with Gem-P ( 25 oxaliplatin, 8 cisplatin; 1 cetuximab-Gem-P) based therapy and 5 patients received CTRT with gemcitabine $300 \mathrm{mg} / \mathrm{m} 2$ once a week. Response rate to neo adjuvant therapy was seen in 5 (13\%) complete response, 17 (45\%) partial response, 9 stable disease, $5(13 \%)$ progressive disease and was not assessed in 2 patients. Overall clinical benefit rate $(\mathrm{CR}+\mathrm{PR}+\mathrm{SD})$ was $82 \%$. Of the 24 patients who underwent surgery, 21 (87\%) had curative surgery and 3 were not operable. This report of the use of neo adjuvant chemotherapy in patients with locally advanced GBC has encouraging results and prospective randomized studies are planned in future to validate the benefits seen.

\section{Chemoradiotherapy}

There is limited data in the treatment of GBC with chemo radiation in the neo adjuvant scenario. A few reports have 
included GBC along with pancreatic carcinoma, hence no meaningful conclusion can be drawn from such studies [31].

Arextabala [32] et al. reported a prospective trial to evaluate the effect of neo adjuvant chemo-radiation on GBC. Patients with incidentally diagnosed GBC after surgery were included; a total of 23 patients were recruited. Chemotherapy was administered using 5-fluorouracil in continuous infusion for five days and radiotherapy upto $45 \mathrm{~Gy}$. Overall survival of these patients was compared with 19 patients who did not undergo radiotherapy in the same institution. 14 patients underwent surgery; at a follow-up of 43.8 months five patients were still alive. It was concluded that chemo radiation had no significant positive effect on survival. On the contrary, the treated patients were reported to have an inferior survival.

An update of another study [33] was presented at the Indian chapter of International hepato pancreatico biliary association (IHPBA) in 2011. They reported results of 14 patients treated with concurrent chemo radiation with Gemcitabine $300 \mathrm{mg} /$ $\mathrm{m} 2$ every week. The data is presented in table 2 in comparison with other reports and a recent report of the efficiency of neo adjuvant chemotherapy in GBC [30]. Studies are needed to assess the resectability rate and information on downsizing post neo adjuvant therapy.

\section{Treatment of Advanced Disease}

Jaundice due to biliary obstruction is the presenting complaint in 30 to 60 percent of patients with GBC; the cause most often is infiltration of the common hepatic duct by tumor.[34] Stenting from a percutaneous or endoscopic approach is usually preferred over biliary bypass surgery. Drainage of just 30 percent of the liver parenchyma (can be accomplished by unilateral drainage of one lobe) is adequate to reduce jaundice and pruritus. Percutaneous and endoscopic methods of biliary drainage were compared in a trial in which 54 patients with GBC and a Bismuth type II or III biliary obstruction who were inoperable were randomly assigned to percutaneous trans hepatic biliary drainage or endoscopic stenting [35]. Successful drainage was achieved more frequently with percutaneous drainage (89 versus 41 percent), and cholangitis was a more frequent complication of endoscopic stenting (48 versus 11 percent). Stent occlusion rates (32 versus 39 percent) and survival (60 days in both groups) were not significantly different.

\section{Chemotherapy}

Reported response rates with chemotherapy in patients with GBC are in the range of 50 to 60 percent. There is limited data assessing the impact of treatment on overall survival. In the only randomized trial comparing chemotherapy (gemcitabine plus oxaliplatin [GEMOX] or 5-FU plus leucovorin) against supportive care alone in 81 patients with inoperable GBC, median OS was 4.5, 4.6, and 9.5 months in the supportive care, FU/leucovorin and GEMOX groups, respectively [36].

In previous studies, response rates for 5-FU by itself or 5FU-based combination treatment ranged from 0 to 34 percent, and median survival was less than six months. Capecitabine is an active agent in GBC. In a study of 63 patients with hepatobiliary carcinoma, which included eight with GBC, capecitabine $\left(2,000 \mathrm{mg} / \mathrm{m}^{2}\right.$ daily for 14 of every 21 days) produced a response in four (50 percent) of the patients with GBC, two of which were complete [37].

Infusional 5-FU has been combined with cisplatin in at least two trials. In one, 5 -FU $\left(1 \mathrm{gm} / \mathrm{m}^{2}\right.$ by continuous infusion daily for 5 days) along with cisplatin $\left(100 \mathrm{mg} / \mathrm{m}^{2}\right.$ on day 2$)$ caused partial remission in six patients ( 24 percent); one was a long-term survivor after administration of additional local therapy. Median survival for patients with GBC was 11.5 months. [38] In another report, ECF regimen as compared to 5-FU along with leucovorin and etoposide (response rate 19 versus 15 percent, median overall survival nine against 12 months, respectively). ECF was associated with significantly less acute toxicity [39].

Table 2 Neoadjuvant treatment in gall bladder cancer

\begin{tabular}{|c|c|c|c|c|c|c|c|c|}
\hline $\begin{array}{l}\text { Author, } \\
\text { year [ref] }\end{array}$ & Design & $\begin{array}{l}\text { Total } \\
\text { patients }\end{array}$ & $\begin{array}{l}\text { Baseline } \\
\text { disease status }\end{array}$ & Regimen & $\begin{array}{l}\text { Surgery } \\
\text { done }[\%]\end{array}$ & $\begin{array}{l}\text { Clinical benefit rate } \\
{[\mathrm{CR}+\mathrm{PR}+\mathrm{SD}]}\end{array}$ & $\begin{array}{l}\text { Median } \\
\text { follow up }\end{array}$ & Survival \\
\hline Aretxabala 1999 [50] & Prospective & 18 & $\begin{array}{l}\text { Post simple } \\
\text { cholecystectomy }\end{array}$ & $\begin{array}{l}\text { EBRT } 45 \text { Gy } \\
\text { with } 5 \mathrm{FU} \text { CI }\end{array}$ & $13(72 \%)$ & NA & 24 months & $38 \%$ \\
\hline Aretxabala 2004 [32] & Retrospective & 23 & $\begin{array}{l}\text { Post simple } \\
\text { cholecystectomy }\end{array}$ & $\begin{array}{l}\text { EBRT } 45 \text { Gy } \\
\text { with } 5 \mathrm{FU} \mathrm{CI}\end{array}$ & $14(60 \%)$ & & 43.8 months & $22 \%$ \\
\hline Engineer 2011 [33] & Prospective & $14^{\mathrm{a}}$ & Locally advanced & $\begin{array}{l}\text { EBRT } 45 \text { Gy with } \\
\text { Gemcitabine }\end{array}$ & $6(43 \%)$ & & & $35 \%$ \\
\hline Sirohi 2013 [30] & Retrospective & 33 & Locally advanced & $\begin{array}{l}\text { Gemcitabine- } \\
\text { Platinum }\end{array}$ & $24(72 \%)$ & $82 \%$ & 8.5 months & 31.7 months \\
\hline
\end{tabular}

${ }^{\text {a }}$ Unpublished data from an ongoing study, based on personal communication

$E B R T$ : external beam radiotherapy, $5 F U$ : 5-fluorouracil, $C R$ : complete response, $P R$ : partial response, $S D$ : stable disease 
Table 3 Chemotherapy in advanced GBC

\begin{tabular}{|c|c|c|c|c|c|c|c|c|}
\hline \multirow[t]{2}{*}{ Author (Ref) } & \multirow[t]{2}{*}{ Total patients } & \multirow[t]{2}{*}{ No GBC } & \multirow[t]{2}{*}{ Treatment } & \multirow[t]{2}{*}{ Control } & \multirow[t]{2}{*}{ Median FU up (mo) } & \multirow[t]{2}{*}{ End point } & \multicolumn{2}{|l|}{ Outcome } \\
\hline & & & & & & & Treatment & Control \\
\hline Valle [8] & 410 & 148 & $\mathrm{Gem}+\mathrm{Cis}$ & Gem & 8.2 & OS & 11.7 months & 8.3 months \\
\hline Okusaka [51] & 84 & 32 & $\mathrm{Gem}+\mathrm{Cis}$ & Gem & na & $1-y$ OS & $39 \%$ & $31 \%$ \\
\hline Riechelmann [41] & 75 & 27 & Gem + Cap & na & 9.5 & OS & 12.7 months & na \\
\hline Knox [52] & 45 & 21 & Gem + Cap & na & 11 & OS & 14 months & na \\
\hline Cho JY [53] & 44 & 7 & Gem + Cap & na & na & OS & 14 months & na \\
\hline Iyer RV [54] & 12 & na & Gem + Cap & na & 18.2 & OS & 14 months & na \\
\hline Thongprasert S [55] & 40 & 1 & $\mathrm{Gem}+\mathrm{Cis}$ & na & na & OS & 8.4 months & na \\
\hline Meyerhardt JA [56] & 33 & na & $\mathrm{Gem}+\mathrm{Cis}$ & na & na & OS & 9.7 months & na \\
\hline Kim ST [57] & 29 & 10 & $\mathrm{Gem}+\mathrm{Cis}$ & na & 10 month & OS & 11 months & na \\
\hline André T [44] & 33 & 19 & $\mathrm{Gem}+\mathrm{Ox}$ & na & na & OS & 15.4 months & na \\
\hline Harder [58] & 31 & 10 & $\mathrm{Gem}+\mathrm{Ox}$ & na & na & OS & 11 months & na \\
\hline Verderame [59] & 24 & 9 & $\mathrm{Gem}+\mathrm{Ox}$ & na & 13 & OS & 12 months & na \\
\hline Doval DC [60] & 30 & 30 & $\mathrm{Gem}+\mathrm{Cis}$ & na & na & OS & 4.6 months & na \\
\hline Gallardo [61] & 26 & 26 & Gem & na & na & OS & 7 months & na \\
\hline Sharma A [36] & 81 & 81 & $\mathrm{Gem}+\mathrm{Ox}$ & $\mathrm{BSC} / 5 \mathrm{FU}$ & 9 months & OS & 9.5 months & 4.5 months \\
\hline
\end{tabular}

Gem: Gemcitabine, Cis: cisplatin, Cap: capecitabine, Ox: oxaliplatin, mos: months, $F U$ : follow-up, BSC: best supportive care, 5-FU : 5-fluorouracil, na: not available

In another trial, capecitabine $\left(1,000 \mathrm{mg} / \mathrm{m}^{2}\right.$ twice daily on days 1 to 14$)$ along with oxaliplatin $\left(130 \mathrm{mg} / \mathrm{m}^{2}\right.$ over 1 hour on day 1) was administered to 65 patients with biliary tract tumors, 27 with GBC, the rest were cholangiocarcinoma [40]. Of the 27 patients with GBC, there was one complete and seven partial responders; another nine had stable disease (total disease control rate 63 percent). The median survival was 11.3 months.

Gemcitabine in combination with Capecitabine is also active. Gemcitabine $\left(1,000 \mathrm{mg} / \mathrm{m}^{2}\right.$ on days 1 and 8$)$ plus capecitabine $(650 \mathrm{mg} / \mathrm{m} 2$ twice daily for 14 of every 21 day cycle) was well tolerated. There were 22 objective responses (three complete), which were seen. The median progressionfree and overall survival rates were 6.2 and 12.7 months, respectively.[41] In another study of 24 patients with GBC, treated with the same doses of gemcitabine but a higher dose of capecitabine $\left(1,000 \mathrm{mg} / \mathrm{m}^{2}\right.$ twice daily for 14 of every 21 days), one-third had a partial response, and the median survival was 16 months [42].

The superiority of gemcitabine along with cisplatin over gemcitabine alone was shown in the multicenter ABC-02 trial, in which a total of 410 patients with locally advanced ( 25 percent) or metastatic bile duct $(n=242)$, gallbladder $(n=148)$ or ampullary $(n=20)$ carcinoma were randomly assigned to six courses of cisplatin $\left(25 \mathrm{mg} / \mathrm{m}^{2}\right)$ followed by gemcitabine $\left(1,000 \mathrm{mg} / \mathrm{m}^{2}\right)$ on days 1 and 8 , every 21 days, or gemcitabine alone $\left(1,000 \mathrm{mg} / \mathrm{m}^{2}\right.$ days $1,8,15$, every 28 days) [8].

At a median follow-up of 8.2 months, median overall survival was much greater with combination therapy (11.7 versus 8.1 months), as was median PFS (8 versus 5 months).

Table 4 Targeted therapy in advanced biliary cancers

\begin{tabular}{|c|c|c|c|c|c|c|c|}
\hline \multirow[t]{2}{*}{ Author (Ref) } & \multirow[t]{2}{*}{ Total patients } & \multirow[t]{2}{*}{ No GBC } & \multirow[t]{2}{*}{ Chemotherapy } & \multirow[t]{2}{*}{ Targeted agent } & \multirow[t]{2}{*}{ End point } & \multicolumn{2}{|l|}{ Outcome } \\
\hline & & & & & & Study & Control \\
\hline Gruenberger [62] & 30 & $\mathrm{Na}$ & GEMOX & Cetuximab & $\mathrm{RR}$ & $63 \%$ & na \\
\hline Lee $[63]$ & 268 & 82 & GEMOX & Erlotinib & PFS/OS & 5.8/9.5 months & 4.2/9.5 months \\
\hline Jensen [64] & 46 & na & GEMOX + CAP & Panitumumab & PFS at 6 months & $74 \%$ & na \\
\hline Sohal [65] & 35 & 0 & GEMIRI & Panitumumab & PFS at 5 months & $69 \%$ & na \\
\hline Zhu [66] & 35 & $\mathrm{Na}$ & GEMOX & Bevacizumab & PFS & 7 months & na \\
\hline Bekaii-Saab [67] & 28 & 7 & none & Selumetinib & $\mathrm{RR}+\mathrm{SD}$ & $80 \%$ & na \\
\hline
\end{tabular}

GEMOX: gemcitabine-oxaliplatin, $C A P$ : capecitabine, GEMIRI: gemcitabine- irinotecan, $P F S$ : progression-free survival, $R R$ : response rate, $S D$ : stable disease, $O S$ : overall survival, mos: months 
Toxicity was comparable in both groups except for significantly higher rates of grade 3 or 4 neutropenia with gemcitabine along with cisplatin ( 25 versus 17 percent), and of grade 3 or 4 abnormal liver function with gemcitabine alone (27 versus 17 percent).

A meta-analysis combining the data from the two available randomized trial in biliary cancer was reported recently [43]. Gemcitabine in combination with cisplatin showed a significant improvement in PFS [hazard ratio $(\mathrm{HR})=0.64,95 \%$ confidence interval (CI) $0.53-0.76$, $P<0.001]$ and $\mathrm{OS}(\mathrm{HR}=0.65,95 \%$ CI $0.54-0.78$, $P<0.001)$ over gemcitabine alone. This effect was most marked in patients with good performance status. Improvement in progression free and OS was seen both in cholangiocarcinomas and GBC. The subgroups least likely to benefit included patients with ampullary tumours and poor performance status.

Gemcitabine/cisplatin combination has not been compared to other gemcitabine combinations (eg, with capecitabine, leucovorin-modulated 5-FU, or oxaliplatin) or capecitabine along with oxaliplatin in randomized trials.

Oxaliplatin and Gemcitabine was studied in a phase II study, the response rate was about 36 percent with $26 \%$ stable disease. The median survival duration was 15.4 months using every 2 weekly gemcitabine $\left(1,000 \mathrm{mg} / \mathrm{m}^{2}\right.$ day 1$)$ and oxaliplatin $\left(100 \mathrm{mg} / \mathrm{m}^{2}\right.$ day 2$)$ in a group of 33 previously untreated patients with advanced biliary cancer (19 with GBC) with a good performance status, and a serum bilirubin level $<2.5$ times normal.[44] Table 3 summarizes some of the available studies of chemotherapy in advanced biliary cancer.

\section{Targeted Therapy}

Some reports suggest benefit from blockade of the epidermal growth factor receptor (EGFR) by the oral tyrosine kinase inhibitor erlotinib.[45] In one report, 42 patients with advanced biliary cancer (not stratified according to primary site), 57 percent had received prior chemotherapy, received erlotinib (150 mg daily). There were three partial responders (two with documented expression of EGFR) and seven patients remained progression-free at six months. All responders had mild (grade 1 or 2) skin toxicity [45].

The efficacy of bevacizumab, a monoclonal antibody targeting VEGF, along with erlotinib was addressed in a multinational phase II study [46]. Fifty-three patients with advanced cholangiocarcinoma $(n=43)$ or GBC $(n=10)$ received bevacizumab ( $5 \mathrm{mg} / \mathrm{kg}$ every two weeks) along with erlotinib (150 mg once daily). Nine patients achieved $\mathrm{PR}$, which was sustained for more than four weeks in six patients (12 percent), with a median response duration of 8.4 months.
Table 4 summarizes some of the available studies using targeted therapy in advanced biliary cancer.

\section{Conclusion}

Early detection and radical resection for GBC offers the only chance of cure. Unfortunately due to delay in presentation most patients have nodal or distant metastasis and prognosis is poor even after complete resection. Studies of gallbladder cancers alone have reported worse outcomes compared to studies including cholangiocarcinoma. Due to its varied epidemiology and aggressive behaviour GBC has to be studied exclusively and separately from other biliary cancers. The role of radiotherapy in incompletely operated GBC needs to be addressed in a randomized trial. Chemotherapy in the neo adjuvant or adjuvant setting has to be studied in well designed randomized trials to establish optimal treatment. The BILCAP [47] study which is randomizing patients with resected biliary tract cancers to oral capecitabine versus observation has completed accrual and the results are awaited. Until the trial results are available, watch and wait remains the strategy for resected GBC. Targeted therapy has not made any major impact in this disease and should only be offered to patients in well designed clinical trials. In advanced disease combination of gemcitabine along with platinum is the current standard of care in patients who can tolerate cytotoxic chemotherapy.

\section{References}

1. Mahantshetty UM, Palled SR, Engineer R, Homkar G, Shrivastava SK, Shukla PJ (2006) Adjuvant radiation therapy in gall bladder cancers: 10 years experience at Tata memorial hospital. J Cancer Res Ther 2(2):52-56

2. Jarnagin WR, Ruo L, Little SA, Klimstra D, D'Angelica M, DeMatteo RP et al (2003) Patterns of initial disease recurrence after resection of gallbladder carcinoma and hilar cholangiocarcinoma: implications for adjuvant therapeutic strategies. Cancer 98(8):16891700

3. Murakami Y, Uemura K, Sudo T, Hayashidani Y, Hashimoto Y, Nakamura $\mathrm{H}$ et al (2009) Adjuvant gemcitabine plus S-1 chemotherapy improves survival after aggressive surgical resection for advanced biliary carcinoma. Ann Surg 250(6):950-956

4. Morrow CE, Sutherland DE, Florack G, Eisenberg MM, Grage TB (1983) Primary gallbladder carcinoma: significance of subserosal lesions and results of aggressive surgical treatment and adjuvant chemotherapy. Surgery 94(4):709-714

5. Oswalt CE, Cruz AB Jr (1977) Effectiveness of chemotherapy in addition to surgery in treating carcinoma of the gallbladder. Rev Surg 34(6):436-438

6. Takada T, Amano H, Yasuda H, Nimura Y, Matsushiro T, Kato H et al (2002) Is postoperative adjuvant chemotherapy useful for gallbladder carcinoma? A phase III multicenter prospective randomized 
controlled trial in patients with resected pancreaticobiliary carcinoma. Cancer 95(8):1685-1695

7. Duffy A, Capanu M, Abou-Alfa GK, Huitzil D, Jarnagin W, Fong Y et al (2008) Gallbladder cancer (GBC): 10-year experience at memorial sloan-kettering cancer centre (MSKCC). J Surg Oncol 98(7): 485-489

8. Valle J, Wasan H, Palmer DH, Cunningham D, Anthoney A, Maraveyas A et al (2010) Cisplatin plus gemcitabine versus gemcitabine for biliary tract cancer. N Engl J Med 362(14):12731281

9. Nakeeb A, Tran KQ, Black MJ, Erickson BA, Ritch PS, Quebbeman EJ (2002) Improved survival in resected biliary malignancies. Surgery 132(4):555-563, discission 563-564

10. Mojica P, Smith D, Ellenhorn J (2007) Adjuvant radiation therapy is associated with improved survival for gallbladder carcinoma with regional metastatic disease. J Surg Oncol 96(1):8-13

11. Kraybill WG, Lee H, Picus J, Ramachandran G, Lopez MJ, Kucik N et al (1994) Multidisciplinary treatment of biliary tract cancers. J Surg Oncol 55(4):239-245

12. Gold DG, Miller RC, Haddock MG, Gunderson LL, Quevedo F, Donohue JH et al (2009) Adjuvant therapy for gallbladder carcinoma: the Mayo clinic experience. Int J Radiat Oncol Biol Phys 75(1):150155

13. Todoroki T, Kawamoto T, Takahashi H, Takada Y, Koike N, Otsuka $\mathrm{M}$ et al (1999) Treatment of gallbladder cancer by radical resection. Br J Surg 86(5):622-627

14. Mahe M, Stampfli C, Romestaing P, Salerno N, Gerard JP (1994) Primary carcinoma of the gall-bladder: potential for external radiation therapy. Radiother Oncol J Eur Soc Ther Radiol Oncol 33(3):204208

15. Mehta A, Bahadur AK, Aranya RC, Jain AK (1996) Role of radiation therapy in carcinoma of the gall bladder-a preliminary indian experience. Trop Gastroenterol Off J Dig Dis Found 17(1):22-25

16. Nadler LH, McSherry CK (1992) Carcinoma of the gallbladder: review of the literature and report on 56 cases at the Beth Israel medical center. Mt Sinai J Med N Y 59(1):47-52

17. Kresl JJ, Schild SE, Henning GT, Gunderson LL, Donohue J, Pitot H et al (2002) Adjuvant external beam radiation therapy with concurrent chemotherapy in the management of gallbladder carcinoma. Int $\mathrm{J}$ Radiat Oncol Biol Phys 52(1):167-175

18. Bosset JF, Mantion G, Gillet M, Pelissier E, Boulenger M, Maingon P (1989) Primary carcinoma of the gallbladder. Adjuvant postoperative external irradiation. Cancer 64(9):1843-1847

19. Todoroki T, Kawamoto T, Otsuka M, Koike N, Yoshida S, Takada Y et al (1999) Benefits of combining radiotherapy with aggressive resection for stage IV gallbladder cancer. Hepatogastroenterology 46(27):1585-1591

20. Houry S, Barrier A, Huguier M (2001) Irradiation therapy for gallbladder carcinoma: recent advances. J Hepatobiliary Pancreat Surg 8(6):518-524

21. Czito BG, Hurwitz HI, Clough RW, Tyler DS, Morse MA, Clary BM et al (2005) Adjuvant external-beam radiotherapy with concurrent chemotherapy after resection of primary gallbladder carcinoma: a 23year experience. Int J Radiat Oncol Biol Phys 62(4):1030-1034

22. Cho SY, Kim SH, Park S-J, Han S-S, Kim Y-K, Lee K-W et al (2010) Adjuvant chemoradiation therapy in gallbladder cancer. J Surg Oncol 102(1):87-93

23. Chao TC, Greager JA (1991) Primary carcinoma of the gallbladder. J Surg Oncol 46(4):215-221

24. Itoh H, Nishijima K, Kurosaka Y, Takegawa S, Kiriyama M, Dohba $S$ et al (2005) Magnitude of combination therapy of radical resection and external beam radiotherapy for patients with carcinomas of the extrahepatic bile duct and gallbladder. Dig Dis Sci 50(12):2231-2242

25. Todoroki T, Iwasaki Y, Orii K, Otsuka M, Ohara K, Kawamoto Tet al (1991) Resection combined with intraoperative radiation therapy
(IORT) for stage IV (TNM) gallbladder carcinoma. World J Surg 15(3):357-366

26. Busse PM, Cady B, Bothe A Jr, Jenkins R, McDermott WV, Steele G $\mathrm{Jr}$ et al (1991) Intraoperative radiation therapy for carcinoma of the gallbladder. World J Surg 15(3):352-356

27. Lindell G, Holmin T, Ewers SB, Tranberg K-G, Stenram U, Ihse I (2003) Extended operation with or without intraoperative (IORT) and external (EBRT) radiotherapy for gallbladder carcinoma. Hepatogastroenterology 50(50):310-314

28. Horgan AM, Amir E, Walter T, Knox JJ (2012) Adjuvant therapy in the treatment of biliary tract cancer: a systematic review and metaanalysis. J Clin Oncol 30(16):1934-1940

29. Wang SJ, Lemieux A, Kalpathy-Cramer J, Ord CB, Walker GV, Fuller CD et al (2011) Nomogram for predicting the benefit of adjuvant chemoradiotherapy for resected gallbladder cancer. J Clin Oncol Off J Am Soc Clin Oncol 29(35):4627-4632

30. Sirohi B, Singh A, Seth V. Neoadjuvant therapy in Indian patients with locally advanced gall bladder cancer: Tata Memorial Centre (TMC) experience. J Clin Oncol 322014 Suppl 3 Abstr 379 [Internet]. [cited 2014 Jan 18]; Available from: http://gicasym.org/ content/122842-143

31. De Aretxabala X, Roa I, Berrios M, Hepp J, Gallardo J, Cordova A et al (2006) Chemoradiotherapy in gallbladder cancer. J Surg Oncol 93(8):699-704

32. De Aretxabala X, Losada H, Mora J, Roa I, Burgos L, Yáñez E (2004) [Neoadjuvant chemoradiotherapy in gallbladder cancer]. Rev Médica Chile 132(1):51-57

33. Engineer R, Wadasadawala T, Mehta S, Mahantshetty U, Purandare N, Rangarajan V et al (2011) Chemoradiation for unresectable gall bladder cancer: time to review historic nihilism? J Gastrointest Cancer 42(4):222-227

34. Kumaran V, Gulati S, Paul B, Pande K, Sahni P, Chattopadhyay K (2002) The role of dual-phase helical CT in assessing resectability of carcinoma of the gallbladder. Eur Radiol 12(8):1993-1999

35. Saluja SS, Gulati M, Garg PK, Pal H, Pal S, Sahni P (2008) Endoscopic or percutaneous biliary drainage for gallbladder cancer: a randomized trial and quality of life assessment. Clin Gastroenterol Hepatol Off Clin Pract J Am Gastroenterol Assoc 6(8):944-950

36. Sharma A, Dwary AD, Mohanti BK, Deo SV, Pal S, Sreenivas Vet al (2010) Best supportive care compared with chemotherapy for unresectable gall bladder cancer: a randomized controlled study. J Clin Oncol Off J Am Soc Clin Oncol 28(30):4581-4586

37. Patt YZ, Hassan MM, Aguayo A, Nooka AK, Lozano RD, Curley SA et al (2004) Oral capecitabine for the treatment of hepatocellular carcinoma, cholangiocarcinoma, and gallbladder carcinoma. Cancer 101(3):578-586

38. Ducreux M, Rougier P, Fandi A, Clavero-Fabri MC, Villing AL, Fassone $\mathrm{F}$ et al (1998) Effective treatment of advanced biliary tract carcinoma using 5-fluorouracil continuous infusion with cisplatin. Ann Oncol Off J Eur Soc Med Oncol ESMO 9(6):653-656

39. Rao S, Cunningham D, Hawkins RE, Hill ME, Smith D, Daniel F et al (2005) Phase III study of 5FU, etoposide and leucovorin (FELV) compared to epirubicin, cisplatin and 5FU (ECF) in previously untreated patients with advanced biliary cancer. Br J Cancer 92(9): $1650-1654$

40. Nehls O, Oettle H, Hartmann JT, Hofheinz R-D, Hass HG, Horger MS et al (2008) Capecitabine plus oxaliplatin as first-line treatment in patients with advanced biliary system adenocarcinoma: a prospective multicentre phase II trial. Br J Cancer 98(2):309-315

41. Riechelmann RP, Townsley CA, Chin SN, Pond GR, Knox JJ (2007) Expanded phase II trial of gemcitabine and capecitabine for advanced biliary cancer. Cancer 110(6):1307-1312

42. Cho J-Y, Nam J-S, Park M-S, Yu J-S, Paik Y-H, Lee S-J et al (2005) A Phase II study of capecitabine combined with gemcitabine in patients with advanced gallbladder carcinoma. Yonsei Med J 46(4): $526-531$ 
43. Valle JW, Furuse J, Jitlal M, Beare S, Mizuno N, Wasan H, et al. Cisplatin and gemcitabine for advanced biliary tract cancer: a metaanalysis of two randomised trials. Ann Oncol Off J Eur Soc Med Oncol ESMO. 2013 Dec 18;

44. André T, Tournigand C, Rosmorduc O, Provent S, MaindraultGoebel F, Avenin D et al (2004) Gemcitabine combined with oxaliplatin (GEMOX) in advanced biliary tract adenocarcinoma: a GERCOR study. Ann Oncol Off J Eur Soc Med Oncol ESMO 15(9): 1339-1343

45. Philip PA, Mahoney MR, Allmer C, Thomas J, Pitot HC, Kim G et al (2006) Phase II study of erlotinib in patients with advanced biliary cancer. J Clin Oncol Off J Am Soc Clin Oncol 24(19):3069-3074

46. Lubner SJ, Mahoney MR, Kolesar JL, Loconte NK, Kim GP, Pitot $\mathrm{HC}$ et al (2010) Report of a multicenter phase II trial testing a combination of biweekly bevacizumab and daily erlotinib in patients with unresectable biliary cancer: a phase II Consortium study. J Clin Oncol Off J Am Soc Clin Oncol 28(21):3491-3497

47. NCT00363584. Capecitabine or Observation After Surgery in Treating Patients With Biliary Tract Cancer [Internet]. Available from: http://clinicaltrials.gov/ct2/show/NCT00363584?term= BILCAP+trial\&rank=1

48. Ben-David MA, Griffith KA, Abu-Isa E, Lawrence TS, Knol J, Zalupski $\mathrm{M}$ et al (2006) External-beam radiotherapy for localized extrahepatic cholangiocarcinoma. Int J Radiat Oncol Biol Phys 66(3):772-779

49. González ME, Giannini OH, González P, Saldaña B (2011) Adjuvant radio-chemotherapy after extended or simple cholecystectomy in gallbladder cancer. Clin Transl Oncol Off Publ Fed Span Oncol Soc Natl Cancer Inst Mex 13(7):480-484

50. De Aretxabala X, Roa I, Burgos L, Cartes R, Silva J, Yañez E et al (1999) Preoperative chemoradiotherapy in the treatment of gallbladder cancer. Am Surg 65(3):241-246

51. Okusaka T, Nakachi K, Fukutomi A, Mizuno N, Ohkawa S, Funakoshi A et al (2010) Gemcitabine alone or in combination with cisplatin in patients with biliary tract cancer: a comparative multicentre study in Japan. Br J Cancer 103(4):469-474

52. Knox JJ, Hedley D, Oza A, Feld R, Siu LL, Chen E et al (2005) Combining gemcitabine and capecitabine in patients with advanced biliary cancer: a phase II trial. J Clin Oncol Off J Am Soc Clin Oncol 23(10):2332-2338

53. Cho JY, Paik YH, Chang YS, Lee SJ, Lee D-K, Song SY et al (2005) Capecitabine combined with gemcitabine (CapGem) as first-line treatment in patients with advanced/metastatic biliary tract carcinoma. Cancer 104(12):2753-2758

54. Iyer RV, Gibbs J, Kuvshinoff B, Fakih M, Kepner J, Soehnlein N et al (2007) A phase II study of gemcitabine and capecitabine in advanced cholangiocarcinoma and carcinoma of the gallbladder: a singleinstitution prospective study. Ann Surg Oncol 14(11):3202-3209

55. Thongprasert S, Napapan S, Charoentum C, Moonprakan S (2005) Phase II study of gemcitabine and cisplatin as first-line chemotherapy in inoperable biliary tract carcinoma. Ann Oncol Off J Eur Soc Med Oncol ESMO 16(2):279-281

56. Meyerhardt JA, Zhu AX, Stuart K, Ryan DP, Blaszkowsky L, Lehman N et al (2008) Phase-II study of gemcitabine and cisplatin in patients with metastatic biliary and gallbladder cancer. Dig Dis Sci 53(2):564-570

57. Kim ST, Park JO, Lee J, Lee KT, Lee JK, Choi S-H et al (2006) A Phase II study of gemcitabine and cisplatin in advanced biliary tract cancer. Cancer 106(6):1339-1346

58. Harder J, Riecken B, Kummer O, Lohrmann C, Otto F, Usadel H et al (2006) Outpatient chemotherapy with gemcitabine and oxaliplatin in patients with biliary tract cancer. $\mathrm{Br} \mathrm{J}$ Cancer 95(7):848-852

59. Verderame F, Russo A, Di Leo R, Badalamenti G, Santangelo D, Cicero G, et al. Gemcitabine and oxaliplatin combination chemotherapy in advanced biliary tract cancers. Ann Oncol Off J Eur Soc Med Oncol ESMO. 2006 Jun;17 Suppl 7:vii68-72.

60. Doval DC, Sekhon JS, Gupta SK, Fuloria J, Shukla VK, Gupta S et al (2004) A phase II study of gemcitabine and cisplatin in chemotherapy-naive, unresectable gall bladder cancer. Br J Cancer 90(8): 1516-1520

61. Gallardo JO, Rubio B, Fodor M, Orlandi L, Yáñez M, Gamargo C et al (2001) A phase II study of gemcitabine in gallbladder carcinoma. Ann Oncol Off J Eur Soc Med Oncol ESMO 12(10):1403-1406

62. Gruenberger B, Schueller J, Heubrandtner U, Wrba F, Tamandl D, Kaczirek K et al (2010) Cetuximab, gemcitabine, and oxaliplatin in patients with unresectable advanced or metastatic biliary tract cancer: a phase 2 study. Lancet Oncol 11(12):1142-1148

63. Lee J, Park SH, Chang H-M, Kim JS, Choi HJ, Lee MA et al (2012) Gemcitabine and oxaliplatin with or without erlotinib in advanced biliary-tract cancer: a multicentre, open-label, randomised, phase 3 study. Lancet Oncol 13(2):181-188

64. Jensen LH, Lindebjerg J, Ploen J, Hansen TF, Jakobsen A (2012) Phase II marker-driven trial of panitumumab and chemotherapy in KRAS wild-type biliary tract cancer. Ann Oncol Off J Eur Soc Med Oncol ESMO 23(9):2341-2346

65. Sohal DPS, Mykulowycz K, Uehara T, Teitelbaum UR, Damjanov N, Giantonio BJ et al (2013) A phase II trial of gemcitabine, irinotecan and panitumumab in advanced cholangiocarcinoma. Ann Oncol Off J Eur Soc Med Oncol ESMO 24(12):3061-3065

66. Zhu AX, Meyerhardt JA, Blaszkowsky LS, Kambadakone AR, Muzikansky A, Zheng H et al (2010) Efficacy and safety of gemcitabine, oxaliplatin, and bevacizumab in advanced biliary-tract cancers and correlation of changes in 18-fluorodeoxyglucose PET with clinical outcome: a phase 2 study. Lancet Oncol 11(1):48-54

67. Bekaii-Saab T, Phelps MA, Li X, Saji M, Goff L, Kauh JSW et al (2011) Multi-institutional phase II study of selumetinib in patients with metastatic biliary cancers. J Clin Oncol Off J Am Soc Clin Oncol 29(17):2357-2363 